\title{
Progestins and Preterm Birth
}

\author{
Helen Y. How ${ }^{1}$ and Baha M. Sibai ${ }^{2}$ \\ ${ }^{1}$ Norton Healthcare System, Louisville, Ky, \\ ${ }^{2}$ Department of Obstetrics and Gynecology, \\ University of Texas Health Sciences, Houston, Texas,
}

USA

\section{Introduction}

Premature delivery (PTD), defined as birth prior to 37 weeks' gestation, remains one of the major problems that lead to perinatal morbidity and mortality in the developed countries (Goldenberg et al., 2008). It affects approximately $12.7 \%$ of all deliveries in the United States and $4.4-8.2 \%$ in many other developed countries such as Australia, New Zealand, Sweden, Canada and Japan (Hamilton et al., 2006; Jenkins et al., 2006; Morken et al., 2005; Health Canada 2003). One third of these occur before 34 weeks' gestation (Amon, 1999; Behrman \& Butler et al., 2007). In the United States, the preterm birth (PTB) rate has increased more than $30 \%$ since 1984 and equates to nearly 500,000 PTBs each year (March of Dimes, 2007). This prematurity rate has been increasing probably as a result of delayed child bearing, increased frequency of multifetal pregnancies from assisted reproductive technology (Tough et al., 2002; Reynolds et al.,2003), general non-interventional approach at or beyond 34 weeks' gestation and the increase in labor inductions and cesarean deliveries including those medically indicated (Damus et al., 2008).

Prematurity causes an estimated $60-80 \%$ of all neonatal deaths of non-anomalous infants in developed countries (Guyer et al., 1997). Neonatal mortality is directly correlated with gestational age (GA) at delivery. For example, the mortality rate for infants born at less than 32 weeks' gestation is almost 70 times the rate of a term infant, and for infants born less than 37 weeks' gestation it is 15 times the term infant rate (2.6/1000 live births)(March of Dimes Birth Defects Foundation, 2005). Reported neonatal morbidity is also a major concern, especially for infants born at less than 32 weeks' gestation. Neonatal complications include intraventricular hemorrhage (IVH), necrotizing enterocolitis (NEC), respiratory distress syndrome (RDS), bronchopulmonary dysplasia (BPD), jaundice and anemia (Behrman and Butler et al., 2007). Economically, care for these infants is responsible for an estimated $\$ 51,600$ investment per child in neonatal care, contributing more than $\$ 26$ billion to annual healthcare costs in the US (Behrman and Butler et al., 2007). Among the infants who survive, $10 \%-15 \%$ are burdened with significant handicaps, such as cerebral palsy, mental retardation, retinopathy, or hearing impairment (Gluckman \& Hanson, 2004). More importantly, low birth weight (LBW) infants who are spared significant neonatal morbidity are at higher risk for cardiovascular disease (myocardial infarction, stroke, and hypertension) and diabetes as adults (Gluckman \& Hanson, 2004). Therefore, greater attention should be focused on very PTBs $<32$ weeks' gestation, because, although this group represents only $1-2 \%$ of all deliveries, it accounts for about $60 \%$ of perinatal mortality 
and nearly $50 \%$ of all long term neurological morbidity (Hack \& Fanaroff, 1999). Judgment on the success of any preventative treatment should focus on deliveries occurring before 33 completed weeks of gestation, when the morbidity and mortality rates are high (Campbell, 2011). Preterm delivery is due to either spontaneous preterm labor (PTL) (40\%-50\%), spontaneous preterm premature rupture of membranes (PPROM) $(25 \%-40 \%)$, or obstetrically indicated PTD $(20 \%-25 \%)$ as a result of maternal, placental or fetal complications (preeclampsia, renal disease, diabetes mellitus with vasculopathy, placenta previa or abruption, and fetal growth restriction). (Tucker et al., 1991).

Although secondary and tertiary interventions such as antenatal corticosteroids, postnatal surfactant, and improved neonatal care have led to reduced morbidity and mortality caused by PTB, effective primary preventive interventions have remained elusive. Encouragingly, accumulating data suggest that progestins may be effective in preventing PTB. The exact mechanism of progesterone in prevention of PTB is not known. Previous studies have demonstrated a number of actions which support gestation (Henderson \& Wilson, 2001; Karalis et al., 1996) and inhibit uterine activity, including actions that relax smooth muscle in the pregnant uterus (Lye \& Porter et al., 1978), prevents formation of myometrium gap junction (Garfield et al., 1982) and oxytocin receptors (Fuchs et al., 1983), blockade of the effects of oxytocin on the myometrium (Grazzini et al., 1998), as well as having immunosuppressive activity against activation of $\mathrm{T}$ lymphocytes (Siiteri \& Seron-Ferre , 1981; Garfield et al., 1980). Studies have suggested that a significant portion of spontaneous $\mathrm{PTB}<34$ weeks' gestation has an infectious or inflammatory etiology. In many patients with infection, elevated levels of lipoxygenase and cyclooxygenase pathway products can be demonstrated (Romero et al., 1989). There are also increased concentrations of cytokines in the amniotic fluid of such women. It is possible that progesterone's anti-inflammatory or immunosuppressive activity may underlie the improvement seen in women with a previous spontaneous PTB < 34 weeks' gestation; however, this remains speculative.

\section{Pharmacokinetics of progestins}

Progestins are available in natural or synthetic formulations for oral, intramuscular (IM) or vaginal administration in the form of suppository or gel. Natural (micronized) progesterone is an exact duplicate of the progesterone produced in the corpus luteum and placenta. It is therefore more readily metabolized by the body and is associated with minimal side effects. The two naturally occurring products include progesterone and 17-hydroxyprogesterone. The plasma concentration will depend on the dose and route of administration, eg, oral (3-6 ng/ml @100 mg and 30 ng/ml @ 200 mg), transdermal(3 ng/ml @ 45 mg), vaginal cream (19 ng/ml @ 300 mg) or gel (3.9 ng/ml @ 90 mg), vaginal (10-19 ng/ml @ 100 mg, 17-34 ng/ml @ $400 \mathrm{mg})$ or rectal (15-52 ng/ml @ $100 \mathrm{mg})$ suppository, IM (40-50 ng/ml @ $100 \mathrm{mg}$ ) and sublingual ( $5 \mathrm{ng} / \mathrm{ml} @ 10 \mathrm{mg}$ dose). The time to peak plasma concentration is longest with 90 mg vaginal gel @ 7 hours and shortest with 200 mg oral micronized progesterone @ 0.8 hour. The vaginal suppository (100mg and $400 \mathrm{mg}$ ) and $100 \mathrm{mg}$ rectal suppository is about 4 hours and the IM route (100 mg) takes about 2-8 hours (Murray, 1998).

Synthetic progestins are progesterone derivatives and 19 nortestosterone derivatives; their chemical structure is very similar to that of the natural progesterone. 17 alpha hydroxyprogesterone caproate (17OHP-C) is a 17- hydroxyprogesterone derivative; it is the most commonly used synthetic progestin given intramuscularly to prevent PTB. It has been isolated from both adrenal glands and corpora lutea. The synthetic caproate ester is inactive 
when given by mouth but works as a long-acting progestin when administered intramuscularly. Pharmacokinetic studies have shown that once-weekly IM administration of 17OHP-C would provide continuous systemic serum levels of $17 \mathrm{OHP}-\mathrm{C}$. The half-life of 17OHP-C was estimated to be approximately 7.8 days, compared with approximately 35-55 hours for progesterone (Onsrud et al., 1985). The route of administration plays an important role in the drug's safety and efficacy profile. Oral progesterone has not been used for prevention of PTB because of its first-pass hepatic metabolism, lack of efficacy data, high side-effect profile, and extreme variability in plasma concentrations. Transvaginal administration of progesterone avoids first-pass hepatic metabolism and is associated with rapid absorption, high bioavailability, and local endometrial effects (von Eye et al., 2004). It has been shown to provide higher and more sustained progesterone concentrations and is the preferred route of administration in many cases. Although this route offers no local pain and few side effects, it is associated with variable blood concentrations and patient compliance issues, therefore many favor the intramuscular route (Di Renzo et al., 2005; Penzias \& Alper et al., 2003; Posaci et al., 2005).

\section{Trials on the use of progestins and PTB}

The majority or randomized trials evaluated the prophylactic supplementation of progestins in asymptomatic women at high risk for PTB. Women are considered to be at high risk for several reasons, including past history of spontaneous PTB or miscarriages, multiple gestation, short cervical length (CL), cerclage in place and uterine anomalies. Earlier small trials using 17OHP-C showed mixed results; 4 trials reported benefit (LeVine, 1964; Papiernik, 1970; Johnson et al., 1975; Yemini et al., 1985), whereas 2 trials (Hartikainen-Sorri et al., 1980; Hauth et al., 1983) reported no benefit in reducing the risk of PTB. A metaanalysis over two decade ago (Kierse, 1990) showed that progesterone was beneficial in reducing PTL: odds ratio 0.43 (95\% CI, 0.20- 0.89); PTB: odds ratio 0.50 (95\% CI, 0.30- 0.85) and LBW $(<2500 \mathrm{~g})$ : odds ratio 0.50 (95\% CI, 0.27- 0.80). This meta-analysis concluded that progesterone was the only product that had been proven to be of benefit if used prophylactically to reduce the incidence of PTB. Despite this robust evidence-based conclusion, the information remained dormant for more than two decade.

\subsection{Progestins and history of prior PTB}

In 2003, two trials rekindled the interest in progestins to prevent PTB. The MFM Network trial (Meis et al., 2003) was conducted by the National Institute for Child Health and Development (NICHD); it is a prospective double blind randomized placebo-controlled trial on 463-singleton gestation with history of spontaneous PTB. Women were treated with weekly intramuscular injections of $250 \mathrm{mg} 17 \mathrm{OHP}-\mathrm{C}$ or placebo from 16 to 20 weeks' gestation until 36 weeks' gestation or birth. The primary outcome of the study was birth before 37 weeks' gestation. Treatment with 17OHP-C reduced the incidence of delivery before 37 weeks (36.3\% in the $17 \mathrm{OHP}-\mathrm{C}$ group vs. $54.9 \%$ in the placebo group). In addition, there was a reduction in delivery less than 35 weeks' gestation $(20.6 \%$ in the $17 \mathrm{OHP}-\mathrm{C}$ group vs. $30.7 \%$ in the control group) and at less than 32 weeks' gestation $(11.4 \%$ in the 17 OHP-C group vs. $19.6 \%$ in the control group). Also, there was a significant reduction in the incidence of LBW (RR 0.66; 95\% CI, 0.51-0.87) and rates of IVH (RR 0.25; 95\% CI, 0.8-0.82) and need for supplemental oxygen (RR 0.62; CI, 0.42-0.92) in infants of women treated with 17OHP-C. The trial of da Fonseca et al. (da Fonseca et al., 2003) was carried out in Sao Paolo, 
Brazil, comprising 142 women considered to be at high risk of PTB due to previous PTB, cervical cerclage and uterine anomalies. These women were randomized to treatment with either vaginal micronized progesterone suppositories $100 \mathrm{mg}$ daily or placebo between 24 and 34 weeks' gestation. Treatment with vaginal progesterone suppositories reduced the rate of PTB before 37 weeks' gestation $(13.8 \%$ in the progesterone group vs. $28.5 \%$ in the placebo group) and before 34 weeks' gestation ( $2.8 \%$ in the progesterone group vs. $18.6 \%$ in the placebo group). Both studies found a significant reduction in the incidence of PTB (OR 0.47; 95\% CI, 0.31-0.69) (Meis et al., 2003); OR 0.4; 95\% CI, 0.4-0.94 (da Fonseca et al., 2003). Neither study found a reduction in the incidence of spontaneous PTL.

Since the publication of these two double blind placebo controlled studies. The National Institute of Child Health and Development (NICHD), the American College of Obstetricians and Gynecologist (ACOG) and the March of Dimes endorsed the prophylactic use of 17OHP-C in women with history of preterm deliveries, although both studies had several limitations. For example: in the da Fonseca et al (da Fonseca et al., 2003) study, the women were not started on non-bioadhesive progesterone vaginal suppository until late gestation, the mean GA at enrollment was 25.2 weeks in the placebo group and 26.5 weeks in the progesterone vaginal suppositories group. In addition, women who delivered preterm following PPROM were excluded. If these women were included in the analysis, the difference in PTB is no longer statistically significant. In the MFM Network (Meis et al., 2003) study, the women enrolled had high rates of PTB, with $54.9 \%$ of the women who received the placebo injections delivering before 37 weeks' gestation. There are some concerns regarding the vehicle, castor oil, used in IM 17OHP-C. The castor oil is thought to induce labor by stimulating the release of prostaglandins, which might negate the potential beneficial effect of IM 17-OHP-C (Brancazio et al., 1988 and O'Sullivan 2010) but this has not been substantiated. However, this high rate of PTD was most likely related to the history of previous preterm deliveries. The earlier in a pregnancy a PTB occurs, the greater the chance of PTD in a subsequent pregnancy. It should also be noted that the mean duration of gestation at the time of the qualifying delivery was 31 weeks' gestation, and a third of the women enrolled had more than one previous PTB. These women were very high risk, strongly motivated and compliant. Iams (Iams, 2010) feels the reasons are primarily based on the demographics of the patient population as well as the obstetric history and feels that the recurrence rate of $55 \%$ is about one would expect from patients enrolled in the placebo arm. On the other hand, 17OHP-C may not be effective in women with a lower risk of PTB, and most preterm deliveries occur in women with no previous PTB. Therefore, the result of this (Meis et al., 2003) study should be interpreted with caution and may not be generalizable to women with a lower risk of PTB. In addition, although 17-OHP-C significantly reduced the rate of PTB among the women who received it, the rate of PTB in this group remained very high at $36.3 \%$. Thus, the identification of other causes of PTB and other methods of preventing it remains a pressing need. Another noteworthy point is that although the study (Meis et al., 2003) demonstrated a statistically significant reduction in the primary endpoint of PTB prior to 37 weeks' gestation, the reduction in PTBs prior to 35 weeks and prior to 32 weeks' gestation which are better surrogates for significant neonatal morbidity and mortality, were not statistically persuasive. Meis and colleagues (Meis et al., 2003) indicated that based on their study results, it would be necessary to treat five to six women with a previous spontaneous PTD to prevent one birth at $<37$ weeks' gestation, and to treat 12 women to prevent one birth at $<32$ weeks' gestation. In addition, the primary clinical trial did not demonstrate a significant reduction in another secondary endpoint, a composite assessment of infant mortality and morbidity. 
In a subsequent data analysis of the NICHD trial evaluating the benefit of 17OHP-C according to the GA of previous delivery, Spong et al (Spong et al., 2005) reported that progesterone did not significantly improve the GA at delivery in women whose earliest previous delivery was at 34 to 35.9 weeks' gestation. However, the recurrence of PTB was significantly less for women treated with 17OHP-C with GA at the earliest previous spontaneous PTB 20 to 27.9 weeks ( $42 \%$ vs. $63 \%$ ) and 28 to 33.9 weeks ( $34 \%$ vs. $56 \%$ ). From their data, the authors concluded that for the women with earliest previous spontaneous PTB at 20 to 27.9 weeks and 28 to 33.9 weeks, 4.7 and 4.6 women (respectively for each group) would need to be treated with 17OHP-C to prevent one PTB. In 2007, a multinational double blind placebo controlled trial ( $\mathrm{O}^{\prime}$ brien et al., 2007) of 659 women with singleton pregnancies and history of spontaneous PTB demonstrated that daily treatment with $90 \mathrm{mg}$ bioadhesive progesterone vaginal gel ( $8 \%$ Prochieve or Crinone) did not decrease the rate of PTB at $<35$ weeks' gestation. This is in contrast to the previously mentioned trial by da Fonseca et al. (da Fonseca et al., 2003). The treatment was initiated between 18 and 22 weeks' gestation and continued until 37 weeks' gestation. The dose of $90 \mathrm{mg}$ progesterone as a bioadhesive gel used in this trial is the therapeutic equivalent of $600 \mathrm{mg}$ progesterone as vaginal suppositories, much higher than the dose used in the Brazilian trial of da Fonseca et al (da Fonseca et al., 2003).

Five good quality meta-analysis and systematic review (Keirse, 1990; Sanchez-Ramos et al., 2005; Coomarasamy et al., 2006; Mackenzie et al., 2006; Dodd et al., 2008) of randomized controlled trials showed that women who received progestational agents had lower rates of LBW and PTB before 37, 35, 34 and 32 completed weeks' gestation. The dose of the 17OHP$\mathrm{C}$ varied between $100 \mathrm{mg}$ and $1000 \mathrm{mg}$ daily for 3-7 days. The timing of initiation ranged between 8 and $<35$ weeks' gestation. The timing at which it was discontinued ranged between 34 and 37 weeks' gestation or after eight doses of $17 \mathrm{OHP}-\mathrm{C}$ or delivery. The progestational agents other than $17 \mathrm{OHP}-\mathrm{C}$ were medroxyprogesterone, allyslestrenol and progesterone. However, there was no reduction in perinatal morbidity and mortality (Keirse, 1990, Sanchez- Ramos et al., 2005; Mackenzie et al., 2006).

\subsection{Progestins and short cervix}

Recently, ultrasound assessment of CL has emerged as another effective prognosticator for PTB. Fonseca et al. (Fonseca et al., 2007) published a randomized, double blind placebocontrolled trial of 250 women between 22 and 25 weeks' gestation with a short cervix $(\leq 15$ $\mathrm{mm}$ by transvaginal ultrasound). These women were randomized to receive $200 \mathrm{mg}$ micronized progesterone vaginal capsules or placebo every night from 24 to 34 weeks' gestation. There was a significant $40 \%$ reduction in spontaneous PTB at $<34$ weeks in the progesterone group (19\%) compared with placebo group (34\%) (RR 0.56; 95\% CI, 0.36-0.86). The effect was limited to singleton pregnancies, as no significant effect was demonstrable in 24 twin pregnancies with a short cervix included in the study. The study was underpowered to show significant effect on perinatal morbidity and mortality. Similarly, in 2011, an international multi-center prospective randomized, placebo-controlled trial (Hassan et al., 2011) showed a reduction in PTD of $50 \%$ at $<28$ (5.1\% vs. $10.3 \%)$; of $45 \%$ at $<33(8.9 \%$ vs. $13.1 \%)$, and of $38 \%$ at $<35(14.5 \%$ vs. $23.3 \%)$ weeks' gestation with progesterone treatment (90 mg of progesterone in bioadhesive gel daily) in patients between 19 and 24 weeks' gestation whose CL was $10-20 \mathrm{~mm}$. There was also a $53 \%$ reduction in very LBW infants $(6.4 \%$ vs. $13.6 \%)$ as well as a significant reduction in the composite neonatal morbidities indices in the progesterone treated group. Hassan et al. excluded CL $<10 \mathrm{~mm}$ on the 
premise that these patients were less likely to respond to progesterone treatment. This may explain the $50 \%$ higher incidence of PTBs in the placebo group in Fonseca study (Fonseca et al., 2007) as the highest incidence of early PTD occurs with CLs of 0-10 mm.

Vaisbuch et al. (Vaisbuch et al., 2010) had previously demonstrated a high incidence of proinflammatory cytokines in the amniotic fluid of such cases. A combination of antibiotics and increased vaginal dose of progesterone may result in prolongation of pregnancy in women with CL of $<10 \mathrm{~mm}$. A sub-analysis of O'Brien study (DeFranco et al., 2007), found that in women with a $\mathrm{CL}<28 \mathrm{~mm}$, the rate of $\mathrm{PTB}</=32$ weeks' gestation was significantly lower in the progesterone group, with a significant reduction in RDS in the treated group. This study highlights the problem of all the previous therapeutic intervention studies where randomization is based on a history of $\mathrm{PTB}$, as this is likely to have a small impact on the overall rate of spontaneous PTB because fewer than $10 \%$ of spontaneous early PTB occur in women with a previous history. The problem with the DeFranco sub-analysis was that the results of only 46 patients were analyzed (19 in the progesterone group, 27 in the placebo group) and that randomization was based on obstetric history and not on CL. The selection of the $28 \mathrm{~mm}$ cut-off for inclusion in the analysis was generated post-hoc for the simple reason that there were only four women available in the study subgroup with a baseline CL of less than $25 \mathrm{~mm}$. These trials suggest that determination of CL is a powerful method for PTB risk assessment. However, until further trials, routine screening of low risk pregnant women by transvaginal ultrasound of CL is still not recommended at least here in the U.S., because only $1.7 \%(413 / 24,620)-2.3 \%$ (733/32,091) (Fonseca et al., 2007; Hassan et al., 2011) of the patients screened have short cervix in the mid trimester. It is true that an extension of a routine mid trimester ultrasound examination to include a 5 minute transvaginal scan to measure CL would not involve a significant increase in expenditure in UK and European countries (Campbell, 2011); it may not be the case in the U.S. Routine cervical screening is not recommended by the ACOG Committee Opinion (ACOG \#419, 2008). Using statistics from Fonseca et al (Fonseca et al., 2007) trial, the number of women need to be treated to prevent one early birth is only 6.6 (95\% CI, 3.8- 22.8). However because of the low prevalence of a short cervix (approx. 1.5\%) among low-risk women, the number needed to scan is 650 (95\% CI, 379-2248) (Chandiramani, 2007). Nevertheless, many clinicians use vaginal or intramuscular progesterone in women with a true short cervix $(\mathrm{CL}<25 \mathrm{~mm})$ or women with a short cervix who have a cervical cerclage.

A meta-analysis of five randomized control trials (Berghella et al., 2011) including 504 women with previous preterm birth and single gestation with a CL less than $25 \mathrm{~mm}$ at randomization before 24 weeks revealed a 30\% reduction in recurrent PTB at less than 35 weeks' gestation (28\% in the cerclage group and $41 \%$ in the non-cerclage group) and a significant and clinically important $36 \%$ decrease in perinatal mortality and morbidity. It would take approximately 20 cerclage procedures to prevent one perinatal death. Cerclage has not been shown to be beneficial in other populations including women with only previous PTBs, short CL, multiple gestations or other risk factors for PTB. The authors' explanation is that women with previous PTB with painless CL shortening to less than 25 $\mathrm{mm}$ in the subsequent pregnancy before 24 weeks' gestation do have a clinically significant component of cervical insufficiency, and that is why cerclage is beneficial. Base on this data, women with previous spontaneous PTB, between 16 and 34 weeks' gestation, and singleton gestation should be screened for short cervix starting at approximately 16 weeks' gestation and continue every 2 weeks until 23 6/7 weeks' gestation, unless the CL is $25-29 \mathrm{~mm}$, in which case weekly screening is performed. Rafael et al. (Rafael et al., 2011), in a 
retrospective cohort study of 58 women with CL of $<25 \mathrm{~mm}$ at $<236 / 7$ weeks' gestation, found that there was no significant differences in the incidences of spontaneous PTB $<35$, < 32 , or $<28$ weeks' among women with a ultrasound indicated cerclage, regardless of whether or not they received 17OHP-C (15 in the 17OHP-C group vs. 43 in the no 17OHP-C group) during the current pregnancy. Their findings are similar to the results of two other studies concerning 17OHP-C in women with a cerclage in place (Berghella et al., 2010 and Rebarber et al., 2008).

\subsection{Progestins and multiple gestations}

Twin gestation carries one of the highest risks of PTD. An older study prior to the use of cervical ultrasound was performed in twins with 170HP-C (Hartikainen-Sorri et al., 1980). In this study 77 women with twin gestation were treated only during the last trimester up until 37 weeks with injections of $17 \mathrm{OHP}-\mathrm{C}$ or placebo. In this randomized clinical trial there were no differences in outcomes such as RDS or perinatal mortality. Likewise, there was no difference in progesterone level (nmoles/liter) between the two groups. In singleton pregnancies, the rate of spontaneous PTB before 34 weeks' gestation is about $1 \%$, while in twins it is $13 \%$ (To et al., 2006). These investigators carried out a study of CL measurement at 22 - 24 weeks' gestation in 1163 twin gestations. They found that the rate of PTB before 32 weeks' gestation was strongly associated with CL. Using cut-offs of $<25 \mathrm{~mm},<20 \mathrm{~mm}$ and $<15 \mathrm{~mm}$, the respective detection rates of spontaneous PTB before 32 weeks' gestation were $35 \%, 49 \%$ and $67 \%$. Another small randomized clinical trial (Briery et al., 2009) administered $250 \mathrm{mg}$ of $17 \mathrm{a}$-Hydroxyprogesterone IM weekly versus placebo to women with twin gestations. The gestational age at delivery and the incidence of preterm birth at $<35$ weeks were similar between the two groups as was infant weight, Apgar score and composite neonatal morbidity.

Rouse et al. (Rouse et al., 2003) presented the NICHD network data on the use of 17OHP-C in the prevention of PTB in 655 women with twin gestation; the results showed that treatment with $17 \mathrm{OHP}-\mathrm{C}$ starting between 16 and 20 weeks and continued until 35 weeks' gestation did not reduce the rate of PTB in twins. Preterm delivery before 35 weeks' gestation occurred in $41.5 \%$ of the progestin group vs. $37.3 \%$ in the control group. Potential limitations of Rouse trial are: 1 ) less than $10 \%$ of enrolled women had a history of prior PTB; and, 2) they use the same $17 \mathrm{OHP}-\mathrm{C}$ dose $(250 \mathrm{mg})$ in women with twin gestation, when their plasma volume is known to be $20 \%$ greater than that in singleton gestation. A secondary analysis of the NICHD trial (Durnwald et al., 2010) reported that women with twin gestations and a cervical length below the 25th percentile $(32 \mathrm{~mm})$ at $16-20$ weeks $(52 / 221)$ had higher rates of PTB. In this subgroup of women, 17OHP-C did not prevent preterm births $(56 \%)$ before 35 weeks' gestation. A CL above the $75^{\text {th }}$ percentile $(44 \mathrm{~mm})$ at $16-20$ weeks $(53 / 221)$ did not significantly reduce the risk of preterm birth $(37 \%)$ in this high-risk population. The authors attributed this to combination of risk factors, such as multiple gestation and short cervix which may be additive and confer an increased risk for PTB that cannot be overcome by administration of $17 \mathrm{OHP}-\mathrm{C}$. Another possible explanation is that cervical shortening in multiple gestations is related to uterine over distension and that this distention is not progesterone sensitive. They concluded that long cervix (44 mm) at 16-20 weeks' gestation may not provide useful clinical information to the obstetrician regarding risk of preterm delivery in twin gestations. Furthermore, a long cervix is likely only reassuring if it is maintained beyond 24 weeks' gestation as demonstrated by Imseis et al. (Imseis et al., 1997). 
Norman et al. (Norman et al., 2009), randomized 500 women with twin pregnancy to $90 \mathrm{mg}$ vaginal progesterone or placebo daily from $24-34$ weeks' gestation. Again, no effect was seen on the primary outcome of delivery or intrauterine death before 34 weeks' gestation (OR 1.36; 95\% CI, 0.89-2.09). In both trials (Rouse et al and Normal et al), a non-significant increase in intrauterine death was seen in the treatment group. Similarly, Caritis et al. (Caritis et al., 2009) demonstrated no reduction in PTB in women with triplet pregnancies treated with $17 \mathrm{OHP}-\mathrm{C}$. Healthy women $(\mathrm{n}=134)$ with triplets were randomly assigned to weekly intramuscular injections of either $250 \mathrm{mg}$ of $17 \mathrm{OHP}-\mathrm{C}$ or placebo, starting at 16 to 20 weeks' gestation and ending at delivery or 35 weeks' gestation. Eighty-three percent of women in the treatment group vs. $84 \%$ in the placebo group delivered before 35 weeks' gestation. Another double-blind, randomized (2:1) trial by Combs et al (Combs et al., 2010) on triplets showed no statistically significant difference with regard to primary outcome i.e. composite neonatal morbidity in 17OHP-C $(n=56)$ and placebo $(n=25)$ groups $(38 \%$ vs. $41 \%)$.

\section{Timing and duration of the administration of progestin in women with risk factors}

There are 2 published observational data regarding the use of $17 \mathrm{OHP}-\mathrm{C}$ in the prevention of recurrent PTB. Rebarber et al. (Rebarber et al., 2007), in a retrospective analysis of data from 481 women who were enrolled for outpatient weekly IM 17OHP-C administrations. They found that women with elective early cessation of weekly $17 \mathrm{OHP}-\mathrm{C}$ at $<32$ weeks' gestation were significantly more likely to have spontaneous recurrent PTD at $<37$ weeks, $<35$ weeks and $<32$ weeks' gestation when compared to the women who received weekly 17OHP-C injections until PTD or 36.9 weeks. Discontinuation of $17 \mathrm{OHP}-\mathrm{C}$ was defined as being elective when it occurred for any reason other than hospitalization for eminent delivery or an acute condition that led to delivery within 10 days. In this study, whether the elective discontinuation was patient or physician driven is not available from the database. A letter to the AJOG editor, Bernstein (Bernstein, 2008) provided an alternative explanation stating that the 17OHP-C is maybe of no benefit but that the sudden withdrawal of 17OHP-C may be involved in triggering spontaneous PTL. However, most clinicians continue treatment until 37 weeks, with the last injection at 36 weeks, and while the majority begin treatment at 16 weeks, it appears that later initiation of treatment up to 28-30 weeks' gestation may be helpful (Rebarber 2007).

How et al. (How et al., 2007), performed a retrospectively analysis of database of women enrolled for outpatient 17OHP-C prophylaxis for prevention of spontaneous PTB. The data were divided into three groups according to the number of PTB $(1,2,>2)$ and stratified to initiation of 17OHP-C at 16-20.9 weeks' and 21-26.9 weeks' gestation. The authors found that the rates of spontaneous PTB were significantly higher in those with $\geq 2$ PTB ( $n=159,51 \%$ vs. $27 \%$ at $<37$ weeks and $21 \%$ vs. $9 \%$ at $<35$ weeks in the 17OHP-C start at 16-20.9 weeks' gestation group; $18 \%$ vs. $2 \%$ at $<32$ weeks in the 17 OHP-C start at $21-26.9$ weeks' gestation group) as compared to those with one PTB $(n=440)$. There were no significant differences in spontaneous PTB rates according to the time of initiation of 17OHP-C at 16-20.9 weeks' gestation vs. 21-26.9 weeks' gestation. The authors concluded that women with history of $\geq$ 2 PTD have a high risk of recurrent spontaneous PTB at $<37$ and $<35$ weeks despite $17 \mathrm{OHP}-\mathrm{C}$ prophylaxis. Later second trimester initiation of $17 \mathrm{OHP}-\mathrm{C}$ prophylaxis is as effective as initiation in the early second trimester. However, these conclusions should be 
interpreted with caution because data such as baseline $\mathrm{CL}$, the GA or circumstances of the prior PTB, maternal race, and complete neonatal outcomes were not available.

\section{Progestins and threatened or established PTL}

Facchinetti et al. (Facchinetti et al., 2007) reported a randomized clinical trial in which symptomatic women with PTL and intact membranes at 25-34 weeks' gestation were allocated to either observation or intramuscular administration of $341 \mathrm{mg}$ of 17OHP-C twice a week until 36 weeks' gestation or delivery. The rationale for using a higher dose in this trial was the onset of PTL requiring tocolysis. In these patients, cervical ripening and the cascade of PTL was already initiated. In this study, 60 women presenting in PTL, treated with atosiban and not delivering within 48 hours were randomly assigned to either treatment with $17 \mathrm{OHP}-\mathrm{C}(\mathrm{n}=30$, including 16 with $\mathrm{CL}</=25 \mathrm{~mm})$ or expectant management $(\mathrm{n}=30$, including 17 with $</=25 \mathrm{~mm})$. Treatment with $17 \mathrm{OHP}-\mathrm{C}$ was associated with a reduction in the risk of PTD (OR 0.15; 95\% CI, 0.04-0.58). Cervical shortening, as measured by ultrasound performed 7 and 21 days post randomization, was significantly less in the 17OHP-C treated group as compared with placebo.

Another study on progesterone use in patients presenting in PTL was published in 2008 by Borna et al. (Borna \& Sahabi et al. 2008). Women between 24 and 34 weeks' gestation with intact membranes were randomized to receive $400 \mathrm{mg}$ of progesterone vaginal suppository $(n=37)$ vs. no treatment $(n=33)$ within 48 hours of arrest of labor with intravenous magnesium sulfate. Progesterone group demonstrated a longer mean latency until delivery (36 +/- 18 days vs. 24 +/- 27) days. However, it failed to reduce the incidence of readmission for PTL. A Cochrane meta-analysis done in 2010 (Su et al., 2010), suggests that progestational agents may be use in the treatment of threatened and preterm labor. However the number of participants in each included study ranged from 35 and 60. Further larger studies are needed.

\section{Progestins and preterm premature rupture of membranes}

Preterm premature rupture of membranes complicates nearly $3 \%$ of all pregnancies and is responsible for one third of all PTB (Mercer et al., 2003). Overall 75\% deliver within one week after rupture, but approximately $15 \%$ may extend gestation for several weeks (ACOG \#1, 1998; Lieman et al., 2005). Briery et al (Briery et al., 2011) randomized women with PPROM at 20-30 weeks' gestation with fetus in cephalic presentation to receive weekly $17 \mathrm{OHP}-\mathrm{C}(\mathrm{n}=33)$ or placebo $(\mathrm{n}=36)$ in an attempt to prolong the pregnancy. The report showed that there was no difference in GA at the time of delivery or the interval between randomization and delivery between the 2 groups. The neonatal outcome statistics of morbidity and mortality were similar between the two groups. The authors concluded that in patient with PPROM, 17OHP-C did not extend gestation vs. placebo and cannot be recommended for treatment in such women.

\section{Safety and tolerability}

Synthetic progestins, including $17 \mathrm{OHP}-\mathrm{C}$ have been associated with a less desirable sideeffect profile than that of natural progesterone, including mood swings, headaches, bloating, abdominal pain, perineal pain, constipation, diarrhea, nausea, vomiting, joint pain, 
depression, decreased sex drive, difficult or painful intercourse, nervousness, sleepiness, breast enlargement, breast pain, nucturia, dysuria, polyuria, urinary tract infection, allergy, tiredness, dizziness, genital itching, yeast infection, vaginal discharge, fever, flu-like symptoms, back pain, leg pain, sleep disorder, inflammation of a sinus, upper respiratory infection, asthma, acne and pruritus. Although these side effects have been reported with any form of progesterone (for example contraceptive), they rarely are severe and do not usually necessate discontinuing the drug at this dose when given to prevent preterm birth. A case in point, would be the MFM Network trial ( Meis et al., 2003), the most common undesirable side effect was injection site pain $(35 \%)$, injection site swelling (17\%), urticaria $(12 \%)$, pruritus $(8 \%)$, injection site pruritus $(6 \%)$, nausea $(6 \%)$, contusion $(6 \%)$, injection site nodule (4\%), and vomiting (3\%) (FDA, 2006). Meis (Meis et al., 2003) and Heinonen (Heinonen et al., 1977) reported a small, statistically non-significant increased in miscarriage and stillbirths in women receiving progesterone. Data from animal studies, suggest that increased plasma levels of progesterone may influence fetal behavior and induce fetal arousal states (Crossley et al., 1997; Nicol et al., 1997). There were no human data regarding long term outcome of women and infants who were exposed to progesterone in-utero until the published NICHD trial (Northen et al., 2007) reported a comprehensive 4 year follow up of children exposed to 17OHP-C in-utero. The children were 30-64 months of age at the time of the follow-up assessments. Of the 348 eligible surviving children, $278(80 \%)$ were available for evaluation (194 17OHP-C, 84 placebo). No significant differences were seen in health status and conditions, or physical exam, including genital anomalies between 17OHP-C and placebo children. The developmental screen including communication, gross motor, fine motor, problem solving, and personal-social issues was not significantly different between 17OHP-C and placebo group. Therefore, it appears that at least with $17 \mathrm{OHP}-\mathrm{C}$ there are no long term adverse effects in the offspring when used at $250 \mathrm{mg}$ per week.

Retrospective data indicate that $17 \mathrm{OHP}-\mathrm{C}$ exposure may be associated with an increased risk of gestational diabetes (Rebarber et al., 2007; Waters et al., 2009). Hepatic dysfunctions, including cholestasis of pregnancy, have also been reported at a higher rate in women treated with oral micronized progesterone in France (Benifla et al., 1997; Bacq et al., 1997). Weekly IM injections of 17 OHP-C may be undesirable to a portion of the population at risk for PTB. Progesterone administered intramuscularly has been associated with several systemic and local skin complications. Some women may find transvaginal delivery to be more acceptable than injection, but others may not agree. Suppositories can be difficult to place high in the vagina and may liquefy, potentially leads to vaginal discharge, irritation, and infection. Vaginal cream and gel, which do not liquefy and are easier to apply, may alleviate some of the problems associated with transvaginal suppositories. Comparative data on the various methods of administration are thus needed to determine pharmacokinetic or tolerability differences, however, before one method can be recommended over the others.

\section{Cost}

Treatment with 17OHP-C or progesterone provides a significant reduction in the risk of recurrent PTB. In addition, there is a reduction in direct and indirect costs associated with PTD. For women with a prior PTD treated with 17OHP-C, the projected discounted lifetime medical costs of their offspring could be reduced by more than 2 billion dollars annually 
(Bailit \&Votruba, 2007). Three U.S. cost-effective analysis studies using decision analysis have been published (Odibo et al., 2006; Cahill et al., 2010; Werner et al., 2011). Odibo et al. (Odibo et al., 2006) compared the cost-effectiveness of using 17OHP-C for the prevention of PTD in cost-savings in women with prior PTD results in cost-savings in women with prior PTD less than 32 weeks and 32 to 37 weeks' gestation. (Cahill et al., 2010) compared the cost effectiveness of universal cervical screening/vaginal progesterone vs. no screening/no treatment on an estimated annual delivery rate of 4 million. The calculated annual cost, based on spontaneous PTBs $<34$ weeks' gestation and severe morbidity prevented, fell from $\$ 46.2$ billion to $\$ 33.3$ billion annually, an annual saving of $\$ 12.9$ billion, which was greater than calculated savings from 17OHP-C treatment on the basis of maternal history ( $\$ 7.9$ billion) or cervical-length screening in high risk pregnancies ( $\$ 3.9$ billion). Using a mean estimate of $\$ 70$ for the second trimester CL scan and \$206 for vaginal progesterone treatment, Werner et al. (Werner, 2011) analyze their model using data of Fonseca et al. (Fonseca et al., 2007), the cost saving was $\$ 12.1$ million for every 100,000 women in the universal screened/vaginal progesterone group. Whereas, using data of Hassan et al (Hassan et al., 2011), the cost saving was $\$ 19.6$ million per every 100,000 women.

In 2006, a New Drug Approval application was submitted to the FDA for 17 OHP-C, and the rights to produce the drug eventually were bought by KV Pharmaceutical. FDA recommended that the pharmaceutical company perform a confirmatory randomized controlled trial with a larger sample size than the Meis study. Once that confirmatory study was underway and $10 \%$ of the total sample size had been recruited from U.S. sites, the FDA approved Makena under the agency's accelerated approval regulations in February 2011. On February 15, 2011, KV Pharmaceutical announced the price of Makena at $\$ 1500$ per injections, 75-150 times more than what formerly was being charged for the same medication that previously was available through locally regulated compounding pharmacies. The cost of the 17OHP-C was $\$ 10$ to $\$ 20$ per injection or $\$ 200$ or $\$ 300$ per pregnancy and about $\$ 150$ per week when home care agencies were used to provide the necessary services. On April 1, 2011, the ACOG and SMFM state that there is no evidence that Makena is more effective or safer than the currently used compounded version. On the same day, KV pharmaceutical reduced the price of Makena from $\$ 1500$ to $\$ 690$ per injection or $\$ 14,000$ to $\$ 16,000$ per pregnancy. ACOG, SMFM, March of Dimes, American Academy of Family physicians all have responded that this reduction in price is insufficient (Cohen et al., 2011). On May 11, 2011 the pharmacy compounding accreditation board sent a letter to SMFM stating that "unlike most other new FDA approved drugs, the makers of Makena do not have a patent on this preparation. The commercial preparation Makena was approved under the FDA's orphan drug program using an older medication with a formula in the public domain and supported by research conducted by the National Institute of Health. Under the orphan drug program, manufacturers are granted seven years of market exclusivity meaning that they and only they have the ability to promote market and advertise that product for the particular use. While a compounding pharmacy cannot market and promote a commercial competitor to Makena, it can legally compound 17OHP$\mathrm{C}$ on the basis of a prescriber's valid prescription". For comparison, the cost of progesterone USP suppositories is \$1-2 per suppository or \$ 5-10 per week or \$200 per pregnancy, whereas the cost of crinone gel 8\% is $\$ 15$ per week or $\$ 100$ per week or $\$ 2500$ per pregnancy (Silver \& Cunningham, 2011). 


\section{Future of progestins and PTB}

Data has shown that there is a place for progesterone in the prevention of PTB. However, the optimal dosage, route and timely delivery of the drug remain controversial. It is encouraging that there are multiple ongoing trials that should further clarify the role of progesterone in PTB prevention (www.clincialtrials.gov/ct/show and; www.charttrials.abdn.ac.uk/). To et al (To et al., 2006), from the fetal Medicine Foundation (FMF), developed a model combining maternal risk factors with CL and found that the inclusion of maternal age and previous history of PTB improved the prediction. The detection rate of screening for PTD before 32 weeks at a fixed false-positive rate of $10 \%$ was $38 \%$ for maternal factors, $55 \%$ for CL and $69 \%$ for combined testing. This concept is important when considering which patients to include in spontaneous PTB prevention programs.

\section{Conclusions}

In summary, the exact mechanism of progestins on reducing preterm birth is speculative at this point. The absence of effect in multiple gestation together with a positive results in women with historical risk, short cervix and the recent cerclage data, suggests that progesterone's effect on preterm birth rates may be related to reducing inflammation rather than acting as a tocolytic agent (Elovitz \& Gonzalez et al., 2008). More information is needed not only regarding the mechanism of action, but also in regard to maternal outcomes following antenatal therapy, preference by patient in terms of mode of delivery, satisfaction of care, optimal dose, optimal route of administration and optimal gestational age at which to begin therapy ( ACOG \#419, 2008).

Although no specific regimen is cited as superior or preferable (ACOG \#419, 2008), evidence at this time supports prophylactic administration of progesterone be offered to women with a singleton pregnancy and a previous spontaneous PTB and to pregnant women with a short cervix of $</=25 \mathrm{~mm}$ at mid-gestation scan for prevention of PTB (250 mg of weekly IM 17OHP-C or progesterone $100 \mathrm{mg}$ daily vaginally). Current evidence does not support the routine use of progesterone in women with multiple gestations and PPROM nor as a treatment for threatened or established PTL.

\section{References}

ACOG Committee Opinion. (2008). Use of progesterone to reduce preterm birth. Obstet Gynecol. 419,963-5.

ACOG practice bulletin. (1998). Clinical management of preterm premature rupture of membranes. Obstet Gynecol. 1, 848-57.

Amon E. (1999) Preterm labor. In: Medicine of the fetus and mothers. Reece EA, Hobbins JC, eds. pp. 529-579. Philadelphia, PA.

Bacq Y, Sapey T, Brechot MC, et al. (1997) Intrahepatic cholestasis of pregnancy. Hepatology 26,358-64.

Bailit JL, Votruba ME. (2007) Medical cost savings associated with 17 alphahydroxyprogesterone caproate. Am J Obstet Gynecol 196(3),219. e1-7. 
Behrman RE, Butler AS (eds) (2007). Committee on Understanding Premature Birth and Assuring Healthy Outcomes, Board on Health Sciences Policy. Preterm Birth Causes, Consequences, and Prevention, Institute of Medicine of the National Academies. The National Academies Press: Washington D.C.

Benifla JL, Dumont M, Levardon M, et al. (1997) Effects of micronized natural progesterone on the liver during the third trimester of pregnancy. Contracep Fertil Sex. 25,165-9.

Berghella V, Figueroa D, Szychowski JM, et al. (2010) Vaginal Ultrasound Trial Consortium. 17-alpha-hydroxyprogesterone caproate for the prevention of preterm birth in women with prior preterm bith and a short cervical length. Am J Obstet Gynecol 202,351;e1-36.

Berghella V, Rafael TJ, Szychowski JM, et al. (2011) Cerclage for short cervix on ultrasonography in women with singleton gestations and previous preterm birth: a meta-analysis. Obstet Gynecol. 117,663-71.

Bernstein PS. (2008). Withdrawal of 17 alpha-hydroxyprosgesterone: a possible trigger for preterm labor? Am J Obstet Gynecol, 198(2),244; author reply 244-5.

Bonesca EB, Celik E, Parra M. et al. (2007) Progesterone and the risk of preterm birth among women with a short cervix. N Engl J Med. 357,462-9.

Borna S, Sahabi N. (2007) Progesterone for maintenance tocolytic therapy after threatened preterm labour: A randomized controlled trial. Aust N Z J Obstet and Gynaecol. 48(1),58-63.

Brancazio LR, Murtha AP, Heine RP. (2003) Prevention of recurrent preterm delivery by 17 alpha-hydroxyprogesterone caproate. N Engl J Med. 349,1987-8.

Briery CM, Veillon EW, Klauser CK et al. (2009) Progesterone does not prevent preterm births in women with twins. Southern Med J. 2009;102(9):900-904.

Briery CM, Vellon EW, Klauser CK. et al. (2011) Women with preterm premature rupture of the membranes do not benefit from weekly progesterone. Am J Obstet Gynecol. 204,54.31-5.

Cahill AG, Odibo AO, Caughey AB et al. (2010). Universal cervical length screening and treatment with vaginal progesterone to prevent preterm birth: a decision and economic analysis. Am J Obstet Gynecol. 202,:548.e1-8.

Campbell S. (2011). Universal cervical-length screening and vaginal progesterone prevents early preterm births, reduces neonatal morbidity and is cost saving: doing nothing is no longer an option. Ultrasound Obstet Gynecol. 38, 1-9.

Caritis SN, Rouse DJ, Peaceman AM, et al. (2009) Prevention of preterm birth in triplets using 17 alpha-hydroxyprogesterone caproate: a randomized controlled trial. Obstet Gynecol . 113 (2 Pt 1), 285-92.

Chandiramani M. (2007). Progesterone and preterm birth. $N$ Engl J Med. 357(22); correspondence 2306-7.

Cohen AW, Copel JA, Macones GA et al. (2011). Unjustified increase in cost of care resulting from U.S. Food and Drug Administration approval of makena (17 alpha hydroprogesterone caproate). Obstet Gynecol. 117(6), 1408-12.

Combs CA, Garite T, Maurel K, et al. (2010) Failure of 17-hydroxyprogesterone to reduce neonatal morbidity or prolong triplet pregnancy: a double-blind, randomized clinical trial. Am J Obstet Gynecol. 203,248.e1-9. 
Coomarasamy A, Thangaratinam S, Gee H, et al. (2006) Progesterone for the prevention of preterm birth: a critical evaluation of evidence. Eur J Obstet Gynecol Reprod Biol. 129,111-18.

Crossley KJ, Nicol MB, Hirst JJ, et al. (1997) Suppression of arousal by progesterone in fetal sheep. Reprod Fertil Dev. 9,767-73.

da Fonseca E, Bittar RE, Carvalho MHB, et al. (2003). Prophylactic administration of progesterone by vaginal suppository to reduce the incidence of spontaneous preterm birth in women at increased risk: A randomized placebo-controlled, double-blind study. Am J Obstet Gynecol. 188, 419-24.

Damus K. (2008). Prevention of preterm birth: a renewed national priority. Curr Opin Obstet Gynecol. 20, 590-6.

DeFranco EA, O'Brien JM, Adair CD, et al. (2007) Progesterone vaginal gel for the reduction of recurrent preterm birth: primary results from a randomized, double-blind, placebo-controlled trial. Ultrasound Obstet Gynecol. 30:687-96.

Di Renzo GC, Mattei A, Gojnic M, et al. (2005). Progesterone and pregnancy. Curr Opin Obstet Gynecol. 17, 598-600.

Durnwald CP, Momirova V, Rouse DJ, et al., for the Eunice Kennediy Shriver National Institute of Child Health and Human Development Maternal-Feal Medicine Units Network. (2010) Second trimester cervical length and risk of preterm birth in women with twin gestations treated with 17- $\square$ hydroxyprogesterone caproate. The Journal of Maternal-Fetal and Neonatal Medicine. 23(12),1360-4.

Elovitz M, Gonzalez J. (2008). Medroxyprogesterone acetate modulates the immune response in the uterus, cervix, and placenta in a mouse model of preterm birth. J. Matern. Fetal Neonatal Me. 21(4), 223-30.

Facchinetti F, Paganelli S, Comitini G, et al. (2007) Cervical length changes during preterm cervical ripening: effects of 17-alpha-hydroxyprogesterone caproate. Am J Obstet Gynecol. 196,453-4.

FDA issues NDA 21-945. Proposed Indication. "Gestiva is indicted for the prevention of preterm birth in...www.fda.gov/ohms/dockets/ac/06/briefing/2006-422B1-02FDA-background.pdf.

Fonseca EB, Celik E, Parra M. et al. (2007). Progesterone and the risk of preterm birth among women with a short cervix. N Engl J Med. 357,462-9.

Fuchs AR, Peryasamy S, Alexandrova M, et al. (1985). Correlation between oxytocin receptor concentration and responsiveness to oxytocin in pregnant rat myometrium: effects of ovarian steroids. Endocrinology. 113, 742-9.

Garfield RE, Dannan MS, Daniel EE. (1980). Gap junction formation in myometrium: control by estogens, progesterone, and prostaglandins. Am J Physiol. 238, C81-9.

Garfield RE, Puri CP, Csapo AI. (1982). Endocrine, structural, and functional changes in the uterus during premature labor. Am J Obstet Gynecol. 142, 21-7.

Gluckman PD, Hanson MA. (2004). Living with the past: evolution, development and patterns of disease. Science. 305, 1733-6.

Goldenberg RL, Culhane JF, Iams J, et al. (2008). The epidemiology and etiology of preterm birth. Lancet 371, 75-84.

Grazzini E, Guillon G, Mouillac B, et al. (1998). Inhibition of oxytocin receptor function by direct binding of progesterone. Nature. 392, 509-12. 
Guyer B, Martin JA, MacDorman MF, et al. (1997). Annual summary of vital statistics-1996. Pediatrics. 100, 905-18.

Hack M, Fanaroff AA. (1999). Outcomes of children of extremely low birth weight and gestational age in the 1990s. Early Hum Dev. 53, 193-218.

Hamilton, BE, Martin JA, Ventura SJ. (2005). Births: preliminary data for 2005. Natl Vital Stat Rep. 55, 1-18.

Hartikainen-Sorri A-L, Kauppila A, Tuimala R. (1980). Inefficacy of $17 \square$ hydroxyprogesterone caproate in the prevention of prematurity in twin pregnancy. Obstet Gynecol. 56, 692-5.

Hassan SS, Romero R, Vidyadhari D, et al., for the PREGNANT Trial. (2011). Vaginal progesterone reduces the rate of preterm birth in women with a sonographic short cervix: a multicenter, randomized, double-blind, placebo-controlled trial. Ultrasound Obstet Gynecol. 38, 18-31.

Hauth JC, Gilstrap LC III, Brekken AL, et al. (1983). The effect of 17 alphahydroxyprogesterone caproate on pregnancy outcome in an active-duty military population. Am J Obstet Gynecol. 146, 187-90.

Health Canada. Canadian Perinatal Surveillance System. Canadian Perinatal Health Report 2003. Chapter 4;73-6. Available at: http://www.hc.sc.gc.ca/pphb-dgspsp/rhsssg/index.html. Accessed July 10, 2005.

Heinonen PP, Slone D., Shapiro S. (1977). Birth defects and Drugs in Pregnancy. Littleton, Mass. PSG Publishing.

Henderson D, Wilson T. (2001). Reduced binding of progesterone receptor to its nuclear response element after human labor onset. Am J Obstet Gynecol. 194, 579-85.

How HY, Barton J, Istwan N, et al. (2007). Prophylaxis with 17 Alpha-hdroxyprogesterone caproate for prevention of recurrent preterm delivery: Does gestational age at initiation of treatment matter? Am J Obstet Gynecol. 197,260.e1-260.e4.

Iams JD. (2010) Was the preterm birth rate in the placebo group too high in the Meis MFMU Network trial of 17-OHPC? Am J Obstet Gynecol 409-410.

Imseis H, Albert T, Iams J. (1997). Identifying twin gestations at low risk for preterm birth with a transvaginal ultrasonographic cervical measurement at 24 to 26 weeks'; gestation. Am J Obstet Gynecol. 177,1149-55.

Institute of Medicine of the National Academies. Preterm Birth: Causes, Consequences, and Prevention, Washington DC; National Academies Press; 2006. Accessed September 1, 2006. Available at: http://www.iom.edu/CMS/3740/25471/35813.aspx.

Jenkins-Manning, Flenady V. Dodd J, et al. (2006). Care of women at risk of preterm birth: a survey of reported practice in Australia and New Zealand. Aust. NZ J. 46(6), 546-8.

Johnson JWC, Austin KL, Jones CS, et al. (1975). Efficacy of 17 $\square$-hydroxyprogesterone caproate in the prevention of premature labor. N Engl J Med. 293, 675-80.

Karalis K, Goodwin G, Majzoub JA. (1996). Cortisol blockade of progesterone: a possible molecular mechanism involved in the initiation of human labor. Nature Medicine. 2(5), 556-60.

Keirse MJNC. (1990). Progesterone administration in pregnancy may prevent preterm delivery. Br J Obstet Gynecol. 96,275-80.

LeVine L. (1964). Habitual abortion: a controlled clinical study of Progestational therapy. West J Surg Obstet Gynecol. 72, 3036. 
Lieman JM, Brumfield CG, Carlo W et al. (2005). Preterm premature rupture of the membranes: is there an optimal gestational age for delivery? Obstet Gynecol. 105, $12-$ 7.

Lye SJ, Porte DG. (1978). Demonstration that progesterone blocks uterine activity in the ewe in vivo by a direct action on the myometrium. Journal of Reproduction and Fertility. $52,87-94$.

Mackenzie R, Walker M, Armson A, et al. (2006). Progesterone for the prevention of preterm birth among women at increased risk: a systematic review and meta-analysis of randomized controlled trials. Am J Obstet Gynecol. 194, 1234-42.

March of Dimes Birth Defects Foundation. (2005). Accessed July 11. Available at: http:/ / www.marchofdimes.com.

March of Dimes (2007).: United States infant mortality overview. http:/ / www.marchofdimes.com/ peristats/tlanding.aspx?reg=99\&lev=0\&top=6\&s lev $=1 \& \mathrm{tlv}=\mathrm{qf}$,

Accessed May 26, 2007.

Meis PJ, Klebanoff M, Thom E, et al. NICHD MFMU Network. (2003). Prevention of recurrent preterm delivery by 17 alpha-hydroxyprogesterone caproate. $N$ Engl J Med. 348(24), 2379-85.

Mercer BM. (2003). Preterm premature rupture of the membranes. Obstet Gynecol. 101,17893.

Morken N, Killen K, Hagberg H, et al. (2005). Preterm birth in Sweden 1973-2001: rate, subgroups, and effect of changing patterns in multiple births, maternal age, and smoking: preterm delivery. Acta Obstet Gynecol Scand. 84(6), 558-65.

Murray JL (1998). Natural Progesterone: what role in women's health care? Health Primary Care. 1,671-87.

Nicol MB, Hirst JJ, Walker D, et al. (1997) Effect of alteration of maternal plasma progesterone concentration on fetal behavioral state during late gestation. $J$ Endocrinol. 152,379-86.

Norman JE, Mackenzie F, Owen P, et al. (2009) Progesterone for the prevention of preterm birth in twin pregnancy (STOPPIT): a randomized, double-blind, placebocontrolled study and meta-analysis. Lancet. 373:2034-40.

Northen AT, Norman, GS, Anderson K, et al. for NICHD MFMU Network. (2007). Followup of children exposed to 17 Alpha-hydroxyprogesterone caproate compared with placebo. Obstet Gynecol 110,865-72.

O'Brien JM, Adair CD, Lewis DF, e t al. (2007). Progesterone vaginal gel for the reduction of recurrent preterm birth: Impact of gestational age at pevious delivery. Ultrasound Obstet Gynecol. 30,687-96.

Odibo AO, Stamilio DM, Macones GA, et al. (2006). 17 alpha-hydroxyprogesterone caproate for the prevention of preterm delivery: a cost-effectiveness analysis. Obstet Gynecol 108(3 Pt 1):492-9.

Onsrud M, Paus E, Haug E, et al. (1985). Intramuscular administration of hydroxyprogesterone caproate in patients with endometrial carcinoma. Pharmacokinetics and effects on adrenal function. Acta Obstet Gynecol Scand. 64, 519-23. 
O'Sullivan MD, Hehir MP, O'Brien YM, Morrison JC. 17 alpha-hydroxprogesterone caproate vehicle, castor oil, enhances the contractile effect of oxytocin in human myometrium in pregnancy. Am J Obstet Gynecol 2010;202:453.e1-4.

Papiernik E. (1970). Double-blind study of an agent to prevent pre-term delivery among women at increased risk. Schering ed. Series 4. P. 65-68.

Penzias AS \& Alper MM. (2003). Luteal support with vaginal micronized progesterone gel in assisted reproduction. Reprod Biomed Online. 6, 287-95.

Posaci C, Smitz J, Camus M, et al. (2000). Progesterone for the luteal support of reproductive technologies: clinical options. Human Reprod. 15 (suppl I), 129-48.

Progesterone therapy. Progesterone...what is it? (2006). Available at: http:// progesteronetherapy.com/.

Rafael TJ, Dhanya Mackeen A, Berghella V. (2011). The Effect of 17 $\alpha$-Hydroxyprogesterone Caproate on Preterm Birth in Women with an Ultrasound-Indicated Cerclage. Am J Perinatol 28:389-94.

Rebarber A, Cleary-Goldman J, Istwan NB, et al. (2008). The use of 17 alphahydroxyprogesterone caproate $(17 \mathrm{p})$ in women with cervical cerclage. Am J Perinatol 25:271-5.

Rebarber A, Ferrara, LA, Hanley ML, et al. (2007). Increased recurrence of preterm delivery with early cessation of 17-alpha-hydroxyprogesterone caproate. Am J Obstet Gynecol. 196,224.e1-224.e4.

Rebarber A, Istwan N, Russo-Stieglitz K et al. (2007). Increased incidence of gestational diabetes in women receiving prophylactic 17 alpha-hydroxyprogesterone caproate for prevention of recurrent preterm delivery. Diabetes Care. 30,2277-80.

Reynolds MM, Schieve LA, Martin JA, et al. (2003). Trends in multiple births conceived using assisted reproductive technology, United States, 1997-2000. Pediatrics. 111(5), 1159-62.

Romero R, Wu YK, Mazor M. (1989). Amniotic fluid arachidonate lipoxygenase metabolites in preterm labor. Prostaglandins Leukot Essent fatty acids. 36, 69-75.

Rouse DJ, Caritis SN, Peaceman AM, et al.(2007). National Institute of Child Health and Human Developmetn Maternal-Fetal Medicine Units Nretwork. A trial of 17 alphahydroxyprogeterone caproate to prevent prematurity in twins. N Engl J Med 357, 454-61.

Sanchez-Ramos L, Kaunitz AM, Delke I. (2005). Progestational agents to prevent preterm birth: a meta-analysis of randomized controlled trials. Obstet Gynecol. 105,273-9.

Siiteri PK, Seron-Ferre M. (1981). Some new thoughts on the feto-placental unit and parturition in primates. IN: Fetal endocrinology. Novy JM, Reskko AJ, editors. P.1. Academic Press. New York.

Silver RM \& Cunningham FG. (2011). Deus ex Makena? Obstet Gynecol. 117(6), 1263-65.

Spong CY, Meis PJ, Thom EA, et al. (2005). Progesterone for prevention of recurrent birth: Impact of gestational age at previous delivery. Am J Obstet Gynecol. 193,1127-31.

Su LL, Samuel M, Chong YS. (2010). Progestational agents for treating threatened or established preterm labour. (Review) The Cochrane Collaboration. Published by John Wiley \& Sons, Ltd.

To MS, Fonseca EB, Molina FS, et al. (2006). Maternal characteristics and cervical length in the prediction of early spontaneous preterm delivery in twins. Am J Obstet Gynecol. 194:1360-5. 
To MS, Skentou CA, Royston P, et al. (2006). Prediction of patient-specific risk of early preterm delivery using maternal history and sonographic measurement of cervical length: a population-based prospective study. Ultrasound Obstet Gynecol 27,362-7.

Tough SC, Newburn-Cook C, Johnston DW. (2002). Delayed childbearing and its impact on population rate changes in lower birth weight, multiple birth, and preterm delivery. Pediatrics. 109(3), 399-403.

Tucker JM, Goldenberg RI, Davis RO, et al. (1991). Etiologies of preterm birth in an indigent population: Is prevention a logical expectation? Obstet Gynecol. 77, 343-7.

Vaisbuch E, Hassan SS, Mazaki-Tovi S, et al. (2010). Patients with an asymptomatic short cervix $(<$ or $=15 \mathrm{~mm}$ ) have a high rate of subclinical intraamniotic inflammation: implications for patient counseling. Am J Obstet Gynecol 202,433.e1-8.

von Eye Corleta H, Capp E, Ferreira MBC. (2004). Pharmacokinetic of natural progesterone vaginal suppository. Gynecol Obstet Invest. 58, 105-8.

Waters TP, Schultz BAH, Mercer BM. et al. (2009). Effect of 17 alpha- hydroxyprogesterone caproate on glucose intolerance in pregnancy. Obstet Gynecol. 114:45-9.

Werner EF, Han CS, Pettker CM et al. (2011). Universal cervical-length screening to prevent preterm birth:a cost-effective analysis. Ultrasound Obstet Gynecol 38:32-7

Yemini M, Borenstein R, Dreazen E, et al. (1985). Prevention of premature labor by 17 alphahydroxyprogesterone caproate. Am J Obstet Gynecol. 293,675-80. 


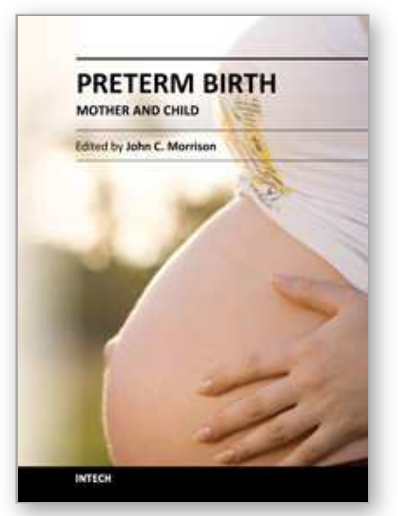

\author{
Preterm Birth - Mother and Child \\ Edited by Dr. John Morrison
}

ISBN 978-953-307-828-1

Hard cover, 368 pages

Publisher InTech

Published online 27, January, 2012

Published in print edition January, 2012

While there are many studies and books regarding preterm birth, both the obstetric and in the neonatal/pediatric literature, what is missing is the integration of data from obstetrics through neonatal course and into pediatrics as the neonate transverses childhood. A continued dialogue between specialties is essential in the battle against preterm birth in an attempt to relieve the effects or after-effects of preterm birth. For all of our medical advances to date, preterm birth is still all too common, and its ramifications are significant for hospitals, families and society in general.

\title{
How to reference
}

In order to correctly reference this scholarly work, feel free to copy and paste the following:

Helen Y. How and Baha M. Sibai (2012). Progestins and Preterm Birth, Preterm Birth - Mother and Child, Dr. John Morrison (Ed.), ISBN: 978-953-307-828-1, InTech, Available from:

http://www.intechopen.com/books/preterm-birth-mother-and-child/progestins-and-preterm-birth

\section{INTECH}

open science | open minds

\section{InTech Europe}

University Campus STeP Ri

Slavka Krautzeka 83/A

51000 Rijeka, Croatia

Phone: +385 (51) 770447

Fax: +385 (51) 686166

www.intechopen.com

\section{InTech China}

Unit 405, Office Block, Hotel Equatorial Shanghai

No.65, Yan An Road (West), Shanghai, 200040, China

中国上海市延安西路65号上海国际贵都大饭店办公楼 405 单元

Phone: +86-21-62489820

Fax: $+86-21-62489821$ 
(C) 2012 The Author(s). Licensee IntechOpen. This is an open access article distributed under the terms of the Creative Commons Attribution 3.0 License, which permits unrestricted use, distribution, and reproduction in any medium, provided the original work is properly cited. 